\title{
ATRAPADOS EN BUSCA DE ASILO. ENTRE LA EXTERNALIZACIÓN FRONTERIZA Y LA CONTENCIÓN SANITARIA
}

\author{
Stuck Seeking Asylum. Between Border Externalization \\ and Sanitary Containment
}

Lorena Mena Iturralde*

Rodolfo Cruz Piñeiro**

\begin{abstract}
Resumen. En la región México-Estados Unidos las políticas para controlar y disuadir los desplazamientos migratorios irregulares han alcanzado también a los buscadores de asilo quienes en los últimos años viven un limbo de inmovilidad y desprotección, ahora agravado por la pandemia de la COVID-19. En este artículo se analizan las implicaciones del programa MPP, del sistema de refugio en México y de la crisis sanitaria sobre las personas con necesidades de protección internacional. Los resultados muestran cómo las restricciones y ralentización de los procesos de asilo y refugio han generado distintas condiciones de atrapamiento, mientras la pandemia acentuó el enfoque de securitización migratoria en torno a un riesgo que debe ser contenido.
\end{abstract}

Palabras clave: refugio; asilo; políticas migratorias; externalización fronteriza; Covid-19.

\begin{abstract}
In the Mexico-United States region, policies to control and deter irregular migratory movements have also reached asylum seekers who in recent years have been living in a limbo of immobility and lack of protection, now aggravated by the COVID-19 pandemic. This article analyzes the implications of the MPP program, the refugee system in Mexico and the health crisis on people with international protection needs. The results show how the restrictions and slowdown of the asylum and refugee processes have generated different entrapment conditions, while the pandemic accentuated the immigration securitization approach around a risk that must be contained.
\end{abstract}

Keywords: refuge; asylum; migration policies; border externalization; Covid-19.

* Departamento de Estudios de Población, El Colegio de la Frontera Norte. Tijuana, Baja California, México. E-mail: Imenadcs@colef.mx. Orcid: https://orcid.org/0000-0003-1158-9458.

** Profesor-Investigador y director del Departamento de Estudios de Población de El Colegio de la Frontera Norte. Tijuana, Baja California, México. E-mail: rcruz@colef.mx. Orcid: https://orcid.org/ 0000-0001-6770-0413. 


\section{Introducción}

En los últimos años, las políticas migratorias implementadas en la región México-Estados Unidos han situado a miles de migrantes irregulares y con necesidades de protección internacional en un limbo donde viven lo opuesto: inmovilidad y desprotección. Con una serie de medidas para frenar o disuadir los flujos de personas que transitan de forma indocumentada por territorio mexicano se han venido consolidando mecanismos para contenerlos, que si bien no son recientes, ahora también afectan a los buscadores de asilo.

Su detonante fue la llamada "crisis de los menores migrantes" ocurrida en el verano de 2014, esto es, la llegada masiva de familias, niños(as) y adolescentes no acompañados a distintos puntos de la frontera sur de los EUA (Estados Unidos de América), quienes en su mayoría procedían de Centroamérica y arribaron con la intención de cruzar a ese país atraídos por la supuesta facilidad de entrar si solicitaban asilo (Seele, 2020; Chishti, Hipsman, 2015).

A raíz de este evento, EUA destinó mayores esfuerzos de sus agencias federales para disuadir estos flujos con deportaciones, la separación de familias y negociaciones con los gobiernos involucrados; mientras que México puso en marcha el Programa Frontera Sur, que se planteaba como un espacio de gobernabilidad fronteriza, pero cuyo trasfondo fue contener el tránsito de migrantes irregulares sin consideraciones sobre su vulnerabilidad (Castañeda, 2016).

Se puede afirmar que desde entonces el derecho a buscar asilo y a disfrutar de él en cualquier país, contemplado en el artículo 14.1 de la Declaración Universal de Derechos Humanos, se ha visto ralentizado y/o restringido. Tal escenario se afianzó en 2019 con los Protocolos de Protección a Migrantes (MPP, por sus siglas en inglés) de los EUA, un mayor número de peticiones de refugio en México, y se agravó con la pandemia por COVID-19, que se erigió como la nueva barrera para limitar las movilidades transfronterizas.

En este artículo se analizan los efectos de las políticas adoptadas por ambos países sobre los flujos migratorios con necesidades de protección internacional, antes y durante la pandemia. El objetivo es evidenciar cómo el régimen de refugiados se convirtió en un campo minado por la progresiva externalización de la frontera estadounidense en Mesoamérica y por prácticas endosadas a la seguridad sanitaria que han tenido diversas implicaciones para las personas migrantes que se han visto atrapadas en México.

Para este trabajo se recurrió a dos acercamientos metodológicos: uno cualitativo, sustentado en la observación y sistematización de testimonios obtenidos en trabajo de campo en albergues de Tijuana (Baja California) y Ciudad Juárez (Chihuahua), así como de voceros de organizaciones que atienden a poblaciones migrantes ${ }^{1}$. Y uno estadístico descriptivo basado en los registros administrativos

1 El trabajo de campo se hizo en el primer trimestre de 2019 e incluyó 22 entrevistas a personas 
de TRAC Immigration de la Universidad de Syracuse de los EUA y de la Comisión Nacional de Ayuda a Refugiados (COMAR) de México, para complementar el análisis sobre los procesos de MPP y las peticiones de refugio, respectivamente.

La estructura del trabajo es la siguiente: primero se revisan algunos antecedentes sobre la externalización fronteriza y el contexto migratorio de tránsito. Luego se analiza la situación de los buscadores de asilo y refugio en la región México-Estados Unidos antes y a partir de la crisis sanitaria, y finalmente unas conclusiones.

\section{La securitización frente a las movilidades en la región}

No es nuevo decir que tras los atentados del 11 de septiembre de 2001, la política exterior de los EUA subordinó con mayor ímpetu los temas de agenda internacional a cuestiones de seguridad nacional (Velázquez, Schiavon, 2008), situando a ciertas movilidades humanas como una amenaza. Lo llamativo es cómo su gestión de la inmigración se ha venido ejerciendo más allá de sus límites territoriales mediante una expansión de labores de control y vigilancia a terceros países, en este caso a México.

Esta externalización responde a un paradigma de securitización que consiste en replantear el ejercicio de la soberanía allende las líneas divisorias de los Estadosnación. En la práctica implica estirar la frontera para multiplicar las instituciones involucradas en su manejo mediante la directa o indirecta cooperación de países del Sur global, que asumen la gestión de flujos migratorios no deseados que se originan en sus territorios o transitan por ellos (Eguren, 2017; Varela, 2015; Baggio, 2010).

De esta forma se ha venido fortificando una frontera vertical (Soriano, 2017), que se traduce en más muros físicos, operativos y detenciones de personas migrantes que son criminalizadas a lo largo del tránsito y que varían en su intensidad, según quienes protagonizan los desplazamientos, la retórica de los gobiernos de turno y la coyuntura. Dicho control también ha justificado que se restrinjan los canales regulares para migrar, que se endurezcan los requisitos para solicitar refugio o asilo, y que se configuren esquemas como tercer país seguro y primer país de llegada, que en la práctica transfieren la responsabilidad de la protección internacional a otros Estados (Ortega, 2020; Frelick et al., 2016)².

adultas de ambos sexos procedentes de países de Centroamérica y El Caribe. Su objetivo era conocer en terreno su situación de tránsito y/o asentamiento en ambas ciudades, como parte de un estudio más amplio sobre la vulnerabilidad de poblaciones migrantes en la frontera norte de México. Los testimonios de organizaciones se obtuvieron entre mayo y septiembre de 2020 en el marco de los seminarios "Poblaciones migrantes y refugiados en el contexto de la pandemia COVID-19", organizados en sesiones virtuales en la institución de adscripción de los autores.

2 El tercer país seguro supone que las personas que solicitan asilo en un país pueden recibir protección en otro que supuestamente ofrece condiciones seguras. El primer país de llegada se basa en que un solicitante debería pedir asilo en el primer país que pise que sea miembro de la Convención de 1951, el cual estaría obligado a atender su solicitud. 
En la región que nos ocupa, la mayoría de flujos irregulares ha sido protagonizado por personas originarias del Triángulo Norte de Centroamérica (Guatemala, Honduras, El Salvador), países afectados durante décadas por conflictos políticos, situaciones de pobreza y desigualdad social, combinados con el escalamiento de la violencia perpetrada por distintos actores (Nájera, 2016). No obstante, en 2014, cuando por primera vez la patrulla fronteriza de los EUA aprehendió a más originarios de Centroamérica que a mexicanos por cruzar sin visas (Romero, Rodríguez, 2016) -entre ellos más de 68 mil menores no acompañados- quedó en evidencia que estas movilidades tomaron otras características en cuanto a su composición, visibilidad y vulnerabilidad, situando en el debate público sus necesidades de protección internacional.

De hecho, entre 2018 y 2019 protagonizaron nuevos desplazamientos en caravanas, esto es, vía terrestre y en grupos grandes que incluyeron numerosas familias y menores, como estrategia para correr menos peligros durante su travesía. Entonces se congregaron más de 6 mil personas en la frontera norte mexicana (EL COLEF, 2018) con la intención de cruzar o de solicitar asilo a los EUA, plantando cara al discurso anti-inmigrante instaurado por Donald Trump desde su ascenso al poder en 2017.

Por parte de México, la labor de embudo migratorio realizada durante el período 2014-2019, se ha patentado con más de 100 mil aprehensiones de centroamericanos por año, según datos de la Unidad de Política Migratoria, Registro e Identidad de Personas (UPMRIP) ${ }^{3}$, pero a la par otros flujos del Caribe, Asia y África cobraron relevancia.

En 2016 sorprendió el inusual ingreso de personas de Haití, quienes llegaron a Tijuana, Mexicali y Nogales con miras a solicitar asilo o una visa humanitaria (humanitarian parole) $^{4}$ a los EUA, tras vivir unos años en Brasil, Chile y otros países que les acogieron tras un terremoto ocurrido en 2010 (Suárez, 2017). Un numeroso grupo fue aceptado en la Unión Americana aquel año, pero iniciado el gobierno de Trump muchos no se presentaron en los puertos fronterizos por temor a ser deportados y se quedaron en México (Albicker et al., 2017).

También está el tránsito de cubanos, que ya venía ocurriendo a cuentagotas a través de redes que operaban en Quintana Roo, pero comenzó a ser más visible a partir de 2014, tras los procesos de negociación entre el gobierno de Cuba y de Ios EUA para restablecer relaciones comerciales. Bajo el temor de que Washington eliminaría la política de "pies secos, pies mojados" ${ }^{5}$-como al final ocurrió en

\footnotetext{
3 Los datos corresponden a eventos de personas remitidas a alojamientos temporales del Instituto Nacional de Migración en tanto no acreditan su situación para regular su estancia o ser retornadas o deportadas. Un migrante puede protagonizar más de una detención.

4 Es un perdón temporal que se otorga a un extranjero inadmisible para que permanezca en el país mientras su caso es revisado por una corte migratoria.

5 Esta política era una interpretación de la Ley de Ajuste Cubano firmada en 1966, la cual garantizaba a los cubanos que lograran pisar los EUA sin tener visa, poder quedarse.
} 
2017- miles se desplazaron por tierra (Villafuerte, García, 2016), alcanzando en 2019 el mayor número de aprehensiones de caribeños en México: 11,068.

En cuanto a los asiáticos, el número de detenciones pasó de 1,046 en 2014 a 5,878 en 2019, destacando personas de India y Bangladesh; mientras en el caso de África, el mayor volumen ocurrió en 2019 (7,065 aprehensiones), principalmente de originarios de Camerún y República Democrática del Congo. Estas movilidades extra continentales, como señala Narváez (2015), obedecen a conflictos armados y violaciones de derechos humanos de distinta índole, y revisten complejidad por su diversidad étnica, cultural e idiomática y por la condición de irregularidad en la que se internan, pues les vuelve potenciales víctimas de tráfico, de trata y de otros riesgos.

En sí, estamos frente a flujos cada vez más heterogéneos, envueltos en múltiples factores de expulsión y que se entremezclan al usar las mismas rutas o al incorporarse en redes ilegales de inmigración, lo que hace más complejo distinguir entre personas que huyen para salvaguardar su seguridad y aquellas que emigran por motivos económicos (Vega, 2017; Espinar, 2010).

Bajo esa línea, los Estados suelen esgrimir discursos que aseguran que estos desplazados no son verdaderas víctimas de persecución, ante lo cual han ido tejiendo esquemas para inadmitirlos en las fronteras y dejarlos "atrapados en la movilidad" (Hess, 2012, p. 434).

\section{El derecho al asilo y refugio en deterioro}

Según la Convención de las Naciones Unidas sobre el Estatuto de los Refugiados de 1951 y su Protocolo de 1967, un refugiado es alguien que debido a fundados temores de ser perseguida por motivos de raza, religión, nacionalidad, pertenencia a determinado grupo social u opiniones políticas, no puede o no quiere regresar a su país de origen (ACNUR, 2011). Aunque dependiendo del contexto, refugio y asilo se entienden de distinta forma.

En América Latina, el asilo remite a la protección que un Estado decide otorgar a una persona perseguida por motivos políticos, mientras que el refugio se asocia con las demás causas que establece la Convención de las Naciones Unidas (Ortega, 2020). En México, ambos derechos están regidos por la Ley sobre Refugiados, Protección Complementaria y Asilo Político, vigente desde 2011; además, este país ha signado la Declaración de Cartagena de 1984, que amplía la definición de refugiado a aquel que ha huido porque su vida ha sido amenazada por violencia generalizada, conflictos internos y la violación masiva de los derechos humanos.

En los EUA, más allá de las causas, el término depende de la localización del peticionario: el refugio es aquel que se solicita desde fuera de ese país, mientras el asilo se tramita en un puerto de entrada (en la frontera mexicana por ejemplo) 
o desde el interior de su territorio dentro de un plazo determinado, según el Servicio de Ciudadanía en Inmigración (USCIS, 2015).

Sin embargo, en los últimos años el principio de no devolución (non-refoulement) que rige este derecho internacional está siendo evadido mediante un "régimen de no entrada" (Castles, 2003, p. 14) diseñado para excluir a potenciales solicitantes.

Tras las caravanas, el gobierno de Trump acusó a México de no impedir las migraciones irregulares por su territorio y tomó medidas unilaterales y coercitivas. Una fue el programa MPP, a través del cual los extranjeros que son inadmisibles y solicitan asilo a los EUA desde su frontera sur son obligados a esperar por sus resoluciones en México (Nielsen, 2019). Y otra la amenaza de imponer aranceles a productos mexicanos si no se frenaban los flujos, ante lo cual, en junio de 2019 ambos países firmaron un acuerdo de colaboración migratoria.

Este pacto provocó un revés en la política de Andrés López-Obrador, quien pasó de una retórica en favor de la protección de los derechos humanos refrendada en el Pacto Mundial para una migración "segura, ordenada y regular" ${ }^{6}$, al control y la contención. A los seis meses de haber iniciado su gobierno hizo cambios en el Instituto Nacional de Migración (INM) y desplegó la Guardia Nacional ${ }^{7}$ en sus fronteras. Aunque en su discurso no se responsabilizó de la decisión de los EUA de implementar el MPP, aceptó proteger los derechos de esos solicitantes enmarcando su papel en el bienestar de éstos, pese a sus limitadas capacidades institucionales, incluso para atender a buscadores de refugio en México, como veremos más adelante.

\section{i) EI MPP, la inaccesibilidad como disuasión}

Antes del acuerdo de colaboración entre ambos países, el programa MPP, llamado también Remain in Mexico (Quédate en México), comenzó a operar en tres puertos fronterizos: Tijuana-San Ysidro, Mexicali-Calexico y Ciudad Juárez-El Paso. Tras su firma se habilitaron Nuevo Laredo-Laredo y Matamoros-Brownsville, y en noviembre, Piedras Negras-Eagle Pass y Nogales-Nogales. Al cierre de 2019 se habían enviado a México a más de 60 mil extranjeros bajo este esquema, mientras otro numeroso grupo se encontraba bajo el mecanismo de metering, esto es, listas informales en las que debían anotarse para acceder a un número de turno con autoridades estadounidenses.

Esto generó un cuello de botella para solicitantes y problemas logísticos en las ciudades fronterizas, donde el mayor peso de la asistencia recayó en organizaciones civiles, con una capacidad máxima de 12 mil personas en sus albergues (Ruiz, 2020). En ese contexto, el trabajo de campo de 2019 ya evidenciaba alojamientos

\footnotetext{
6 Se firmó el 10 de diciembre de 2018 en Marrakech.

7 La conforman miembros de la Policía Federal, Naval y Militar y fue creado en enero de 2019 para prevenir y combatir los delitos con alto grado de violencia.
} 
sobrepasados en número y ciertas particularidades sociodemográficas: en los albergues de Tijuana se hospedaban principalmente centroamericanos(as) con parejas o familias; y en Ciudad Juárez predominaban cubanos(as) adultos(as) que viajaban solos(as). Buena parte de los centroamericanos habían llegado en las caravanas de 2018 y tenían entre dos y cinco meses en esos lugares, mientras los cubanos habían recorrido al menos diez países tras ingresar al continente por Guyana y llevaban hasta dos meses de espera cerca de El Paso, Texas.

La mayoría expresaba la intención de pedir asilo en los EUA y experimentaba un doble atrapamiento: espacial y legal, que se fue intensificando en los siguientes meses a medida que más migrantes subían al norte o eran devueltos a la frontera. En este sentido y con base en testimonios se identificaron tres situaciones: i) personas confinadas a la protección de los albergues, ii) personas con cierta movilidad fuera de esos espacios y iii) buscadores de asilo con o sin asistencia legal.

La primera, retomando el concepto de "atrapados en la movilidad" de Hess (2015), consiste en su estancamiento en zonas precarias y provisionales de asentamiento, debido a sus necesidades de asistencia social, a una condición migratoria irregular cada vez más prolongada en México y a la inseguridad de los contextos de espera. El temor de ser detenidos por la Guardia Nacional o a correr riesgos por su inexperiencia en estas localidades han sido temas latentes y sobre los cuales han alertado organizaciones de derechos humanos (Human Rights First, 2019; Leutert, 2020) para exigir que se derogue el programa "Quédate en México".

Yo no he querido salir [del albergue]. Nosotros queremos ir para Estados Unidos porque es el único país donde nos vamos a sentir seguras (...) estamos buscando protección. No en México, aquí hay mucha violencia. (Migrante cubana en lista de espera entrevistada en Ciudad Juárez, febrero de 2019)

En contraparte, los albergues tuvieron que adaptarse a las necesidades de estas poblaciones, cada vez más heterogéneas y con distintas vulnerabilidades. En Tijuana, la experiencia con los flujos de haitianos de 2016 había fortalecido una red de organizaciones para atender a distintos tipos de migrantes: mujeres, menores, hombres adultos, familias, a diferencia de Ciudad Juárez, donde por la saturación de su único albergue se tuvieron que habilitar nuevos espacios.

La segunda situación de atrapamiento se halló en los migrantes centroamericanos que obtuvieron alguna de las "visas humanitarias" ${ }^{8}$ que otorgó el gobierno mexicano para los llegados en las caravanas, debido a que les daba estatus legal de hasta un año, acceso a CURP $^{9}$ y permiso de trabajar

8 El nombre oficial es Tarjeta de Visitante por Razones Humanitarias y se otorgaron más de 8 mil hasta enero de 2019. Luego se suspendió su emisión para los flujos de tránsito.

9 La Clave Única de Registro de Población es un código alfanumérico de identidad utilizado para identificar oficialmente a residentes y ciudadanos mexicanos. 
con remuneración. Si bien esta opción les dió cierta movilidad espacial y ayudó a algunos a ocuparse, no siempre en el mercado formal, su dependencia a los albergues persitía. Muchos temían que dicho documento afectara sus procesos de asilo en los EUA, al no estar tan desprotegidos o en situación más vulnerable en el lado mexicano, según sus relatos.

Es que en general, la gestión del MPP ha sido confusa en cuanto a documentación para la estancia en México. Quienes no tiene esta visa reciben una Forma Migratoria Múltiple $(\mathrm{FMM})^{10}$ cada que retornan de sus audiencias en los EUA, la cual varía en su temporalidad, según el punto fronterizo y la fecha asignada por la corte de inmigración para una nueva cita, la cual difícilmente es aceptada para rentar vivienda, por empleadores y servicios públicos. "Su situación podría decirse que es de semi-irregularidad", sostiene un representante de la Organización Internacional de las Migraciones (OIM) en México.

A esto se suma la tercera situación: el difícil acceso a asistencia legal para el asilo, un proceso que conlleva que la persona sea citada por un juez de inmigración para defender su caso las veces que sean necesarias, y que puede durar de seis meses hasta varios años (París, Díaz, 2020). Debido a que están fuera de los EUA, contar con abogados de ese país es casi imposible. En respuesta, ciertas organizaciones y abogados pro-bono de ambos lados de la frontera han hecho esfuerzos por brindar acompañamiento en las localidades mexicanas visitando los albergues o adecuando espacios para asesorar sobre este proceso:

La abogada que vino nos dijo 'llamen a este número por si en San Diego los sueltan'. En San Diego hay un albergue, o sea, estamos bien informados. Es más, nos ayudaron a hacer una entrevista como si el agente nos estuviera preguntando. (Migrante hondureño solicitante de asilo entrevistado en Tijuana, marzo de 2019)

No obstante, el gran volumen de casos de MPP y la dinámica transfronteriza en que se desenvuelve ha hecho muy limitada esta cobertura. Según registros de TRAC Immigration las personas bajo este programa han sido devueltas a siete localidades mexicanas, mientras los trámites en las cortes solo se dan en cinco ciudades de los EUA. Hasta septiembre de 2020 había 64.539 procesos, de los cuales el $78 \%$ se destinaron a tribunales de inmigración de El Paso, Brownsville y Laredo (gráfico 1). Estas localidades también registraron el mayor volúmen de ordenes de remoción contra los solicitantes (30,089 en conjunto); es decir, tras atender los casos los jueces decidieron sostener los cargos de no admisibilidad y negar el asilo.

En segundo lugar están los casos pendientes de resolución (21,819 entre las cinco ciudades), mientras los procesos terminados predominan en San Ysidro y Calexico, esto es, que los jueces resolvieron rescindir los casos, hayan comparecido o no a las audiencias, y que las personas ya no son admitidas en los

\footnotetext{
${ }_{10}$ Parte del problema es que la FMM es un documento que se suele entregar a todo extranjero que se interna a México con fines de turismo y no permite actividades remuneradas.
} 
EUA. Para ello no se requiere una orden de remoción porque los MPP ya viven fuera del país (TRAC Immigration, 2020). Por el contrario, los asilos concedidos son ínfimos: 532 entre todas las cortes. Apenas el 0.8\%.

\section{Gráfico 1 - Casos de MPP según estatus y ubicación de las audiencias (2019-2020*)}

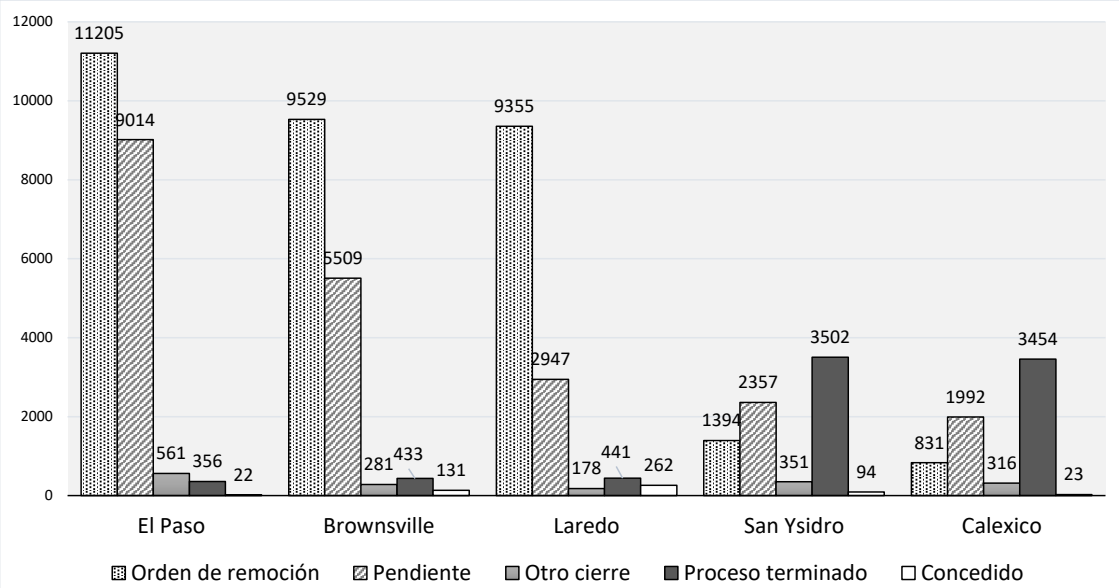

(*) Datos a septiembre. Fuente: Elaboración propia con base en TRAC Immigration.

Estos resultados pueden obedecer a que el 90\% de los procesos de MPP no han contado con representación legal, pero también a una reducción en la cuota de asilados que puede admitir los EUA y a medidas cambiantes para limitar el acceso al sistema. Por ejemplo, está una regla provisional del Department of Homeland Security emitida el 16 de julio de 2019 (Transit-Country Asylum Ban) mediante la cual, extranjeros no mexicanos que llegaran a su frontera sur que no demuestren que solicitaron protección en algún país por el que transitaron y que les fue negada, no son elegibles (Chishti, Bolter, 2020). Un "primer país de llegada" explícito.

En cuanto al seguimiento de audiencias, los registros muestran que el $15 \%$ estaban en espera de su primera cita con un juez de inmigración; el 37\% asistieron a todas las audiencias, mientras el $48 \%$ no se presentaron a su última cita prevista, y fueron objeto de una absentia desicion (decisión en ausencia): el juez emitió orden de deportación o dio por concluidos sus procesos.

Lo último refleja los problemas que han existido para notificar a los solicitantes. En Tijuana y Ciudad Juárez se constató que algunas personas cambian de albergues, de manera que no tienen una dirección permanente donde puedan recibir sus avisos de comparecencia. Además, buena parte de los escritos están en inglés, una limitante adicional teniendo en cuenta que la 
mayoría son de Honduras, Guatemala, Cuba, El Salvador, Ecuador y otros países hispanohablantes.

\section{ii) México, del tránsito al refugio rezagado}

Además de los cambios en los flujos de tránsito otro hecho relevante ha sido el incremento exponencial de las solicitudes para obtener la condición de refugiado en México. En 2013, la COMAR registraba un número incipiente de solicitantes, pero fue escalando en los siguientes años con un despunte a partir de 2016 (8,796), que se triplicó en 2018, y alcanzó un récord de más de 70 mil solicitudes en 2019. Más de 5 mil por ciento de aumento en seis años.

Se atribuye a varios factores: más desplazamientos forzados desde diferentes contextos, el endurecimiento de las políticas de los EUA, y las medidas adoptadas por México para restringir los flujos irregulares, llevando a muchas personas a acogerse a este proceso como destino deseado o como estrategia para evitar ser devueltas, en un contexto donde la detención en la frontera con Guatemala es la norma.

La participación porcentual de peticiones de refugio de personas de Honduras entre 2013 y 2019 ha sido la más importante. De hecho, ha liderado la lista de nacionalidades que se acogen a este derecho, mientras en segundo lugar se ha ubicado El Salvador, excepto en 2017 y 2018 en que fue superado por Venezuela. Tal situación ha implicado un gran desafío en atención y gestión para México, considerando las limitaciones institucionales de la COMAR, que en tres años sufrió una reducción de 25\% de su presupuesto, al pasar de 27.7 millones de pesos en 2017 a 20.8 millones en 2019 (Villaseñor, León, 2019). Y esto pese a que tuvo que ampliar operaciones de cuatro a siete oficinas para atender la creciente demanda ${ }^{11}$.

Como consecuencia, la tramitación de solicitudes ha sido lenta y deficiente, como muestran los datos sobre resoluciones emitidas (gráfico 2). En total, a septiembre de 2020 se habían resuelto 57,907 casos, apenas el 36\% del volumen de peticiones registradas desde 2013 (158,177). Aunque por nacionalidades existen variantes: de las 21,796 decisiones emitidas para personas de Honduras, el $59 \%$ fueron positivas, $29 \%$ negativas y $12 \%$ Protección Complementaria, un estatus que se otorga al extranjero no reconocido como refugiado que evita devolverlo al territorio en donde su vida corre peligro. En cambio, en el caso de Venezuela, de las 12,647 resoluciones emitidas, el 98\% fueron favorables; pero en el caso de Cuba y Haití, $72 \%$ y $81 \%$, respectivamente, negativas.

\footnotetext{
11 Está en Tapachula, Tenosique, Acayucan y Ciudad de México, y desde 2019 en Tijuana, Monterrey y Palenque.
} 


\section{Gráfico 2 - Distribución porcentual de las solicitudes de refugio en México según resolución emitida y nacionalidad (2013 a 2020*)}

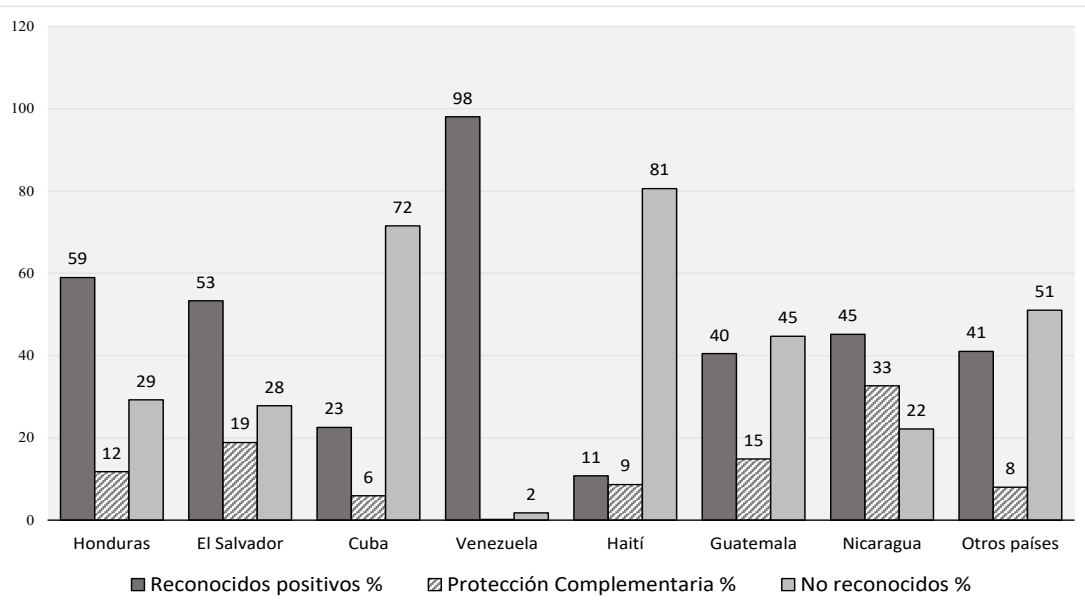

(*) Datos hasta septiembre de 2020. Fuente: Elaboración propia con registros de la COMAR.

Estos datos parecen mostrar una aplicación del refugio que ha sido desigual y discriminatoria según orígenes nacionales. En este caso el Estado ha tenido buenas prácticas frente a la comunidad venezolana que protagoniza una crisis regional de desplazados, aunque en el contexto mexicano esta población en su mayoría llega por vía aérea y pudiera tener más acceso e información sobre este procedimiento, a diferencia de quienes se internan por las fronteras que tras ser detenidos suelen iniciar sus trámites confinados en estaciones del INM, con o sin interés real de acogerse a esta protección.

Según el artículo 24 de la Ley sobre Refugiados y su reglamento, la COMAR tiene un plazo de 45 días hábiles para resolver cada caso, con posibilidades de extenderlo 45 días más. Pero los tiempos de espera mucho antes de la pandemia han estado superando los periodos de ley. Asylum Access (2020) señala que hasta el 25 de octubre de 2019, 13,089 personas que pidieron refugio en 2018 (44\% del total de ese año), llevaban 10 meses o más esperando las decisiones sobre sus casos, y que quizá por ello el $11 \%$ abandonaron o desistieron de sus trámites, como ilustra uno de los casos que hallamos en la frontera norte:

Teníamos la estufita, nuestra cama, ya nos habíamos hecho de cosas. Nosotros queríamos seguir con COMAR, y en eso miramos la caravana que estaba en Puebla, y le digo a mi esposa 'no nos queda de otra y pues vámonos de aquí', y así nos infiltramos. (Migrante hondureño entrevistado en Tijuana, enero de 2019)

Abona a esto que según la normativa los peticionarios están obligados a permanecer en el estado en el cual iniciaron su solicitud hasta que se decida sobre la misma, una restricción que impone una barrera importante para la continuidad de sus procesos y su integración. En efecto, las personas solicitantes deben acudir 
semanalmente a las oficinas de la COMAR o del INM a firmar un registro como prueba de que siguen en la localidad y en el proceso.

Así que su espera no solo está constreñida a plazos en la práctica indefinidos, sino también a un espacio geográfico que quizá no ofrezca oportunidades sociolaborales de asentamiento, a pesar de contar con "visas humanitarias" mientras se resuelve su proceso. Chiapas concentra el mayor volumen $(45,821$ solo en 2019). Un desafío para la sociedad receptora, en cuanto a atención y absorción de esta población. Y para los migrantes otra forma de atrapamiento.

\section{La pandemia, el muro inmunológico}

La crisis de salud por la COVID-19 ha provocado un descalabro en las condiciones de vida de miles y propiciado el surgimiento de una nueva categoría de excluidos por su impacto en distintos aspectos del bienestar. En este escenario, las personas buscadoras de protección que ya experimentaban distintas vulnerabilidades no han quedado exentas, pues la pandemia ha fortalecido la construcción de la otredad migrante como un riesgo que debe ser contenido ahora en nombre de la salud pública. Así, con un "discurso higienista de cierre de fronteras" (León, Contreras, 2020, p. 167) se han erigido muros invisibles a la par de los físicos y barreras normativas que ya existían.

Los testimonios de quienes asisten a estas poblaciones en México hoy dan cuenta de un triple atrapamiento: espacial, legal y sanitario. Una confluencia entre la condición de (in)movilidad, mayor incertidumbre en torno a las estancias y procesos de asilo o refugio, y los "umbrales inmunológicos" (Toro, 2020) representados por el distanciamiento social, que si bien operan como protocolos de salud son otra materialización del enfoque securitario que ha venido imperando en la gestión migratoria.

Para empezar, desde marzo de 2020, cuando se detectó el primer caso de COVID-19 en México, los albergues resintieron su operación al tener que restringir su aforo para evitar hacinamientos y la propagación del virus (Sánchez, 2020). Esto significó no acoger a más personas y reducir la capacidad disponible por no contar con áreas de aislamiento de enfermos. "Tenemos población de alto riesgo: de la tercera edad, con asma, diabetes. Tocó enfocarnos a la prevención", cuenta la fundadora del albergue Espacio Migrante en Tijuana.

Este trabajo a puertas cerradas limitó la asistencia social, no solo para los recién llegados - pues los flujos de tránsito se redujeron, más no se frenaron por completo- sino también para aquellos migrantes, incluso refugiados ya reconocidos, que habían logrado independencia económica y perdieron sus trabajos o la capacidad de sostener una renta y su subsistencia.

En el sur mexicano el cierre de fronteras de Guatemala dejó a centroamericanos varados en Chiapas, tras un vaciamiento de los centros de detención del INM por la contingencia sanitaria, mientras en el norte mexicano 
nuevas acciones por parte de los EUA han presionado más sobre la ya limitada capacidad de atención y sanidad de sus localidades. A partir del 24 de marzo cerró sus fronteras terrestres para cruces no esenciales y suspendió las audiencias de MPP basado en el Título 42, una orden del Centro de Control y Prevención de Enfermedades (CDC, por sus siglas en inglés) que prohíbe el ingreso de personas que potencialmente representan un riesgo para la salud (Gallegos, 2020).

Además bajo esta norma ha realizado deportaciones expeditas hacia México. Según datos de la Oficina de Aduanas y Protección Fronteriza de EUA (CBP por sus siglas en inglés) en el año fiscal 2020, hubo 204,787 expulsiones por su frontera sur bajo el Título 42, y otras 253 mil aprehensiones e inadmisiones. En Ciudad Juárez se tuvo que habilitar un "hotel filtro" en el que pudieran aislarse los migrantes recién llegados que fueran casos sospechosos de COVID-19, mientras en otras ciudades organismos internacionales han cooperado con albergues en la gestión de la contención migratoria y sanitaria, reseña un vocero de Médicos Sin Fronteras.

A diferencia de EUA, que paró los procesos de asilo, México continuó con la recepción de solicitudes de refugio durante la pandemia, aunque suspendió las firmas semanales. Sin embargo, las esperas en el trámite de casos se han prolongado todavía más. La COMAR (2020) anunció que desde el 1 de junio y hasta que las autoridades sanitarias determinen que no existe riesgo epidemiológico, se extendían de manera indefinida los tiempos, por lo que no deberán contarse como hábiles los días que comprenderá dicha suspensión para el cómputo de plazos.

En suma estos estancamientos han generado otros problemas para los buscadores de asilo y refugio. La dificultad de renovar las FMM, para el caso de los MPP, al no poder acreditar una próxima cita en EUA porque no hay audiencias; limitaciones para integrarse en México sin una residencia permanente, para los que optaron por el refugio aquí y siguen esperando resoluciones, y otros casos de irregularidad sobrevenida.

Aunado a ello la pandemia ha profundizado la estigmatización hacia los migrantes y permeado su ya malogrado bienestar social y económico, su inseguridad, salud física y mental.

\section{Conclusiones}

En estas páginas se expuso un panorama de los hechos migratorios más relevantes ocurridos en la región México-EUA antes y durante la pandemia y cómo las respuestas de ambos países para frenar flujos irregulares están afectando a poblaciones necesitadas de protección internacional. Este análisis se enmarca en un contexto global en donde las políticas de refugio han asumido posturas cada vez más restrictivas y están contagiando incluso a países con una tradición de puertas abiertas. 
México, por su situación geoeconómica y política ha mostrado una posición ambigua, ciertamente anclada a una clara e histórica asimetría de poder. Por un lado, ha cooperado con los EUA en su régimen de externalización fronteriza, al reforzar sus controles frente a los desplazamientos humanos que cruzan por su territorio. Además, ha permitido que se transgreda el derecho de las personas obligadas a esperar en México bajo el MPP, pues al admitirlas -si bien como ayuda humanitaria- ha sido copartícipe de violaciones al principio de no devolución.

Pero por otro lado, ha mantenido compromisos alineados a los derechos humanos, tanto en su legislación migratoria y de refugio, como en su retórica. A través de la COMAR ha mostrado apertura para atender el imparable aumento de solicitantes de protección, aunque en los hechos, su capacidad institucional es reducida, provocando un alto número de rezagos.

La Unión Americana ha venido cerrando su sistema de asilo a la par de sus políticas migratorias, con normas que complican acceder a este derecho, especialmente durante la administración de Donald Trump, quien redujo la cuota de refugiados a 18 mil en 2020, la más baja en su historia. La mirada ahora está en el presidente Joseph Biden, quien ha iniciado su administración derogando el programa MPP y declarando que elevaría la cuota de refugiados en $125 \mathrm{mil}$ al año, en sintonía con una crisis mundial de desplazados forzados que Naciones Unidas estimó en más de 80 millones de personas hasta 2020.

Todo ello en el marco de una pandemia, que además de contener ciertas movilidades, alentó la configuración de nuevas barreras para bloquear o ralentizar los procesos de asilo. La crisis sanitaria ha servido para justificar la suspensión de audiencias (en EUA) e indefinir plazos (en México), dejando a las personas peticionarias atrapadas en la espera y desprotección.

En tanto, el peso de la asistencia ha recaído en organizaciones civiles e internacionales, que en medio de la crisis sanitaria han buscado cumplir con su labor humanitaria en localidades que no ofrecen las condiciones necesarias para garantizar la permanencia y seguridad.

Ante el recrudecimiento de los factores de expulsión en distintos países, incluyendo los resultantes de esta pandemia, se avizoran nuevos desplazamientos humanos desde el sur global. Y en este marco, el deterioro del sistema de asilo o refugio supone otras problemáticas: que miles de personas de distintos orígenes seguirán solicitando protección pero no la obtendrán o que muchas optarán por no iniciar estos procedimientos por ser inalcanzables. Es decir, se convertirán en refugiados de facto, cuyo estatus será similar al de migrantes irregulares, que viven en las sombras y corren el riesgo de ser devueltos a sus países. 


\section{Referencias bibliográficas}

ACNUR. Manual y directrices sobre procedimientos y criterios para determinar la condición de refugiado. 2011. Disponible en: <https://www.refworld.org/cgi-bin/texis/ vtx/rwmain/opendocpdf.pdf?reldoc $=y \& d o c i d=50 c 1 a 04 a 2>$. Acceso en: 22.08.2020.

ALBICKER, Sandra; FÉLIX, Carlos; PARÍS; Dolores; PÉREZ, Gabriel; VELASCO, Laura. Emergencia migratoria y solidaridad de la sociedad civil en Tijuana, 2016-2017. Tijuana, México: El Colef, 2017.

ASYLUM ACCESS. Hoja informativa sobre el asilo en México. 2020. Disponible en: $<$ https://asylumaccess.org/wp-content/uploads/2020/01/HOJA-INFORMATIVASOBRE-EL-ASILO-MEXICANO.pdf. >. Acceso en: 18.09.2020.

BAGGIO, Fabio. Fronteras nacionales, internalizadas y externalizadas. In: ANGUIANO, María Eugenia; LÓPEZ, Ana María. Migraciones y fronteras. Barcelona: IcariaCIDOB, 2010, p. 49-73.

CASTAÑEDA, Alejandra. ¿Qué es el programa Frontera Sur?. 2016. Disponible en: $<$ https://observatoriocolef.org/wp-content/uploads/2016/06/BOLET\%C3\%8DN-1Alejandra-Casta\%C3\%B1eda.pdf>. Acceso en: 10.09.2020.

CASTLES, Stephen. La política internacional de la migración forzada. Migración y Desarrollo, n. 1, p. 1-28, 2003.

CHISHTI, Muzaffar; BOLTER, Jessica. Interlocking Set of Trump Administration Policies at the U.S.-Mexico Border Bars Virtually All from Asylum. 2020. Disponible en: $<$ https://www.migrationpolicy.org/article/interlocking-set-policies-us-mexicoborder-bars-virtually-all-asylum>. Acceso en: 20.09.2020.

CHISHTI, Muzaffar; HIPSMAN, Faye. Dramatic Surge in the Arrival of Unaccompanied Children Has Deep Roots and No Simple Solutions. 2014. Disponible en: < https:// www.migrationpolicy.org/article/dramatic-surge-arrival-unaccompanied-childrenhas-deep-roots-and-no-simple-solutions > . Acceso en: 15.09.2020.

COMAR. Extiende Comisión de Ayuda a Refugiados suspensión de plazos de manera indefinida. Comunicado No61. 2020. Disponible en: <https://www.gob.mx/comar/ es/articulos/comunicado-no-61-2020?idiom=es > . Acceso en: 25.09.2020.

EGUREN, Joaquín. Las fronteras y las migraciones. In: ARES, Alberto; EGUREN, Joaquín (coords.). Los movimientos migratorios en las fronteras iberoamericanas. Ciudad de Guatemala: Kamar-OBIMID, 2017, p. 29-43.

EL COLEF. La caravana de migrantes centroamericanos en Tijuana 2018. Diagnóstico y Propuestas de Acción. 2018. Disponible en: <https://www.colef.mx/wp-content/ uploads/2018/12/EL-COLEF-Reporte-CaravanaMigrante-_-Actualizado.pdf >. Acceso en: 22.11.2020.

ESPINAR, Eva. Migrantes y refugiados: reflexiones conceptuales. Obets, Revista de Ciencias Sociales, v. 5, n. 1, p. 35-47, 2010.

FRELICK, Bill; KYSEL, lan; PODKUL, Jennifer. The Impact of Externalization of Migration Controls on the Rights of Asylum Seekers and Other Migrants. Journal on Migration and Human Security, v. 4, n. 4, p. 190-220, 2016. 
GALLEGOS, Rocío. Alarga Estados Unidos la espera de asilo a migrantes enviados a México. La Verdad, 24.07.2020. Disponible en: < https://laverdadjuarez.com/index. php/2020/07/24/alarga-estados-unidos-la-espera-de-asilo-a-migrantes-enviados-amexico/>. Acceso en: 28.09.2020.

HESS, Sabine. De-naturalising transit migration. Theory and methods of an ethnographic regime analysis. Population, Space and Place, v. 18, n. 4, p. 428-440, 2012.

HUMAN RIGHTS FIRST. Orders from Above: Massive Human Rights Abuses Under Trump Administration Return to Mexico Policy. Washington DC: Human Rights First, 2019.

LEÓN, Alejandra; CONTRERAS, Jenyel. La construcción social del peligro migratorio en contextos de crisis globales. Un análisis comparado: Europa Occidenal-Centro y Sur Latinoamericano. Revista Andina de Estudios Políticos, v. 10, n. 1, p. 152-171, 2020.

LEUTERT, Stephanie. Protocolos de Protección a Migrantes: Implementación y consecuencias para los solicitantes de asilo en México. Austin, Texas: Strauss CenterFM4 Paso Libre, 2020.

NÁJERA, Jéssica. El complejo estudio de la actual migración en tránsito por México: Actores, temáticas y circunstancias. Migraciones Internacionales, v. 8, n. 3, p. 255266, 2016.

NARVÁEZ, Juan. Migración irregular extracontinental en México. Apuntes para el diseño de una política y gestión migratoria. Migración y Desarrollo, v. 13, n. 24, p. 117-132, 2015.

NIELSEN, Kirstjen. Department of Homeland Security. 2019. Disponible en: <https:// www.dhs.gov/sites/default/files/publications/19_0129_OPA_migrant-protectionprotocols-policy-guidance.pdf>. Acceso en: 12.09.2020.

ORTEGA, Eliza.¿México como tercer país (in)seguro? El asilo como derecho humano en disputa. México: UNAM-Instituto de Investigaciones Jurídicas, 2020.

PARÍS, María Dolores; DÍAZ, Emiliano. La externalización del asilo a la frontera Norte de México: protocolos de protección al migrante. In: REDODEM. Migraciones en México: fronteras, omisiones y transgresiones. Informe 2019, México: Red de Documentación de las Organizaciones Defensoras de Migrantes, 2020, p. 85-119.

ROMERO, Luis; RODRÍGUEZ, Néstor. Inmigración de menores centroamericanos y reacciones en Estados Unidos. Ecuador Debate, n. 97, p. 123-141, 2016.

RUIZ, Ariel. Un año después del Acuerdo Estados Unidos-México: La transformación de las políticas migratorias mexicanas. 2020. Disponible en: <https://www. migrationpolicy.org/research/un-ano-acuerdo-estados-unidos-mexico $>$. Acceso en: 01.10.2020.

SÁNCHEZ, Laura. Migrantes quedan desamparados ante miedo a coronavirus. Mexicanos contra la corrupción y la impunidad, 25.03.2020. Disponible en: < https:// contralacorrupcion.mx/coronavirus-migrantes-miedo/>. Acceso en: 28.09.2020.

SEELE, Andrew. Un año de cambios profundos en la política migratoria entre Centroamérica, México y Estados Unidos. 2020. Disponible en: <https://www. fundacioncarolina.es/wp-content/uploads/2020/01/AC-2.20.pdf>. Acceso en: 12.09.2020. 
SORIANO, Rosa. La posición geopolítica marroquí como frontera vertical de la Unión Europea. CienciaUAT, v. 12, n. 1, p. 52-69, 2017.

SUÁREZ, Sabrina. La migración haitiana por Iberoamérica y la gestión migratoria mexicana. Madrid: Informe OBIMID, 2017.

TORO, Cecilia. La pandemia, la globalización y las migraciones. Los nuevos enemigos. Revista Aequitas, n. 3, p. 73-80, 2020.

TRAC IMMIGRATION. Details on MPP (Remain in Mexico) Deportation Proceedings. 2020. Disponible en: <https://rac.syr.edu/phptools/immigration/mpp/>. Acceso en: 10.2020.

USCIS. Refugiados o Asilo. 2015. Disponible en: < https://www.uscis.gov/es/programashumanitarios/refugiados-y-asilo>. Acceso en: 02.10.2020.

VARELA, Amarela. La "securitización" de la gubernamentalidad migratoria mediante la "externalización" de las fronteras estadounidenses a Mesoamérica. Contemporánea, 09.12.2015. Disponible en: <https://con-temporanea.inah.gob.mx/ del_oficio/amarela_varela_num4 $>$. Acceso en: 08.09.2020.

VEGA, Daniel. Tendencias y políticas migratorias recientes sobre refugio en México. Odisea. Revista de Estudios Migratorios, n. 4, p. 202-227, 2017.

VELÁZQUEZ, Rafael; SCHIAVON, Jorge. El 11 de septiembre y la relación México Estados Unidos: ¿Hacia la securitización de la agenda? Revista Enfoques, v. 6, n. 8, p. 61-85, 2008.

VILLAFUERTE, Daniel; GARCÍA, María del Carmen. De la crisis de los niños migrantes a la crisis de la migración cubana: intereses geopolíticos y expresiones sociales de la crisis del sistema migratorio Centroamérica-México-Estados Unidos entre 2014 y 2015. Boletín de Antropología Universidad de Antioquia, v. 31, n. 52, p. 16-33, 2016.

VILLASEÑOR, Andrea; LEÓN, Claudia. Una aproximación a los vacíos de protección frente a la crisis humanitaria de personas refugiadas en México: la experiencia desde el terreno. In: ALATORRE, Felipe (ed.). México y la 4T, contradicciones y limites (Análisis plural). Guadalajara: ITESO, 2019, p. 177-187. 